\title{
Visualisation of the diffuse endocrine system
}

\author{
I. M. P. DAWSON
}

From the Department of Pathology, University Hospital, Queen's Medical Centre, Nottingham, UK

Bacon declared that 'the informed mind is more apt to see'; in the matter of detecting endocrine cells within the gastrointestinal tract, though some 400 years in advance of his time, he was correct. Endocrine cells are distinguishable from other gastrointestinal epithelial cells by the presence within their cytoplasm of secretory granules, and with due care and expectation of their presence these may often be recognised in conventionally stained paraffin embedded material, as many 19th and early 20th century histologists appreciated (see Clara, 1957). Not all endocrine cells, however, have granules which are recognisable, nor is differentiation between the shape and content of one granule and another possible on conventional haematoxylin and eosin staining. The purpose of this presentation is briefly to review the different types of endocrine cell found in the gut and the techniques by which one may be separated from another (Dawson, 1970, 1976).

Endocrine cells in the gut are constructed as variants on a common pattern. They tend to be pear shaped or triangular, with a broad base abutting onto the basement membrane and a narrow apex which usually reaches the intestinal lumen and often bears microvilli. There is a conspicuous rough endoplasmic reticulum and Golgi, and mitochondria rich in decarboxylases and esterases. The most significant feature, however, is the presence within the cytoplasm of storage granules surrounded by a lipoprotein envelope, which tend to be especially numerous at the base rather than at the apex of each cell. Endocrine cells are classified by the content of these granules which can potentially be determined either by histochemical or by immunocytological techniques. Since granule size, shape, and density also seem to be related to granular content, ultrastructural studies may afford a separate means of identifying cell function.

The granules in most endocrine cells in the gut contain a polypeptide hormone. Some contain an identifiable biological amine of which 5-hydroxytryptamine (5HT) is the most important. It is the supposed ability of all endocrine cells to be able to decarboxylate amine precursors which has led to their being referred to as APUD (Amine Precursor Uptake and Decarboxylation) cells, a term which
Pearse and his co-workers have enthusiastically embraced in their many detailed studies of an evergrowing family (Pearse, 1968, 1969). Since not all cells which secrete polypeptide hormones can be shown to decarboxylate and store amine precursors, I prefer the non-committal term endocrine cells; certainly endocrine cell tumour, when the precise secretion (for example, insulinoma) cannot be named, is preferable to the ugly word Apudoma.

\section{Histochemical techniques for endocrine cells}

These are divisible into those which are specific, which include techniques for amines, and those which are at best semi-specific though of value for screening purposes, which include all of those used for peptides.

\section{TECHNIQUES FOR AMINES}

Biological amines will condense with specific aldehydes and acids producing compounds which fluoresce (Ewen and Rost, 1972); individual compounds have differing excitation and emission spectra which allow amine identification by spectrofluorimetry. In practice, most biological amines diffuse extremely rapidly from their containing granules, and special methods of freeze-drying and vapour fixation with particular aldehydes are needed to preserve them in their original location and concentration (Corrodi and Jonsson, 1967; Björklund and Falck, 1968; see also Dawson, 1976). Since these are research techniques they will not be discussed further. 5HT, however, diffuses slowly, and early and adequate formaldehyde or glutaraldehyde fixation converts it to a $\beta$-carboline (Barter and Pearse, 1955) within the granules. This compound emits a yellow fluorescence when excited with blue-violet light and also acts as a reducing agent, reducing silver salts to metallic silver (argentaffin reaction) and ferric ferricyanide to ferric ferrocyanide (Schmorl's reaction). It will also couple with diazonium salts to yield insoluble coloured azo dyes (diazo reaction). The fluorescent emission is specific; the other reactións are technically non-specific, but in practice 5HT is the only substance present in sufficient quantity within granules after standard fixation to 
react with formaldehyde and produce a reducing substance, so that the reaction can be regarded as specific for 5HT within the human alimentary tract. Silver 'staining' is discussed in more detail in the next section. Singh's (1964) modification of the original Masson-Hamperl technique gives a minimum of background staining, and is the technique which I prefer for 'argentaffinity'.

\section{TECHNIQUES FOR POLYPEPTIDE HORMONES}

There are no histochemical techniques which are specific for individual polypeptide hormones; metachromatic, basic dye, and silver and lead haematoxylin methods are of value as screening techniques, but are only at best semi-specific for granule identification. All of them depend on the fact that polypeptides have anionic reactive side chains.

\section{Metachromatic techniques}

A chemical dye which is metachromatic exhibits one colour in its monomer form and a different colour when dye molecules polymerise. Basophilic and metachromatic cationic stains attach to anionic polypeptide side chains, and if these reactive anionic sites are spatially close enough metachromatic dye units attached to them polymerise and the dye colour changes. Toluidine blue, cresyl violet, and certain metachromatic fluorochromes are all valuable in this respect. Such techniques are probably showing carboxyl, sulphate, and phosphate groupings. They are best used preceded by mild acid hydrolysis which removes unwanted basophilia resulting from reactive groups in nucleic acid and acid polysaccharides and may also unmask other side chain carboxyl groups (Solcia et al., 1968; Bussolati et al., 1969). They are valuable as screening techniques in that only coiled polypeptides within granules are likely to have anionic reactive groups sufficiently close together to produce polymerisation of metachromatic cationic dyes, but they do not allow the identification of individual amino-acids or amino-acid sequences, and therefore cannot separate one polypeptide from another. They are more time consuming than lead haematoxylin or argyrophil techniques as simple screening procedures.

\section{Silver techniques}

In all silver techniques the silver solution used first attaches to tissue components. Argentaffin techniques, in which silver salts are reduced to metallic silver by a reducing agent already present within cell components (in the case of 5HT-containing cells a 5HT-formaldehyde compound, $\beta$-carboline), have already been discussed. In argyrophil methods silver salts are reduced by an external, added reducing agent. Argyrophil techniques are valuable, but infuriating, principally because we do not know at all precisely what is happening. A number of different silver salts are used, including silver proteinate (whose precise structure is unknown), and aqueous and alcoholic silver nitrate (see review by Dawson, 1976), which are assumed to attach themselves to disulphide bonds and probably to amino-acid side chains. Since argyrophil reactions are normally performed on tissues already fixed in a variety of different fixatives which themselves attach to these side chains, it follows that some side chains will be preserved and others blocked before the silver solution is applied. This at least partly explains why different techniques of fixation and 'staining' produce widely differing results. They are potentially more valuable than metachromatic methods for there is good evidence that when the fixative and the silver salt employed are specific, at least some polypeptides can be partially identified (for example, gastrin appears always to give a positive Grimelius (1968) reaction after formaldehyde fixation), but one can only compare like techniques with like. The method of Hellerström and Hellman (1960), for example, gives differing results on Bouin- and $10 \%$ formol saline-fixed material, and results differ from those found with the Sevier and Munger (1965) technique even when fixation has been identical. Much research needs still to be done; meanwhile the silver nitrate technique of Grimelius (1968) after formaldehyde fixation provides a reliable screening method. Silver proteinate solutions should, in my view, be avoided.

\section{Lead haematoxylin}

This stain, first described by Solcia et al. (1969), is similar in action to basic and metachromatic dyes in that it combines with carboxyl and carboxy-amino groups and gives a deeper staining after acid hydrolysis. Like them it is at best semi-specific but forms a useful screening technique for endocrine cells.

In summary, I would regard the histochemical N techniques for 5HT as diagnostic within the human gut, and those for endocrine cell granules as of definite but limited value. I do not myself use meta- $\omega$ chromatic techniques initially; I regularly use lead haematoxylin and the Grimelius (1968) silvero technique to 'screen' for endocrine cells, though $\underset{\mathbb{D}}{\complement}$ there are some cells whose granules do not stain $\stackrel{+}{+}$ with either method. In particular sites specific silver ${ }^{T}$ techniques applied after appropriate fixation can be $\frac{+}{\mathbb{D}}$ used with care to identify provisionally a particular $\stackrel{\odot}{\stackrel{9}{\oplus}}$ endocrine cell; for example, in the gastric antrum $\stackrel{\mathbb{Q}}{\varrho}$ after formaldehyde fixation, cells which are numerous, Grimelius positive, diazo negative, and do not show aldehyde induced fluorescence (thus ruling out 5HT-응 containing cells) can be provisionally classified as 
probably containing gastrin, since endocrine cells giving similar staining reactions but containing other polypeptides are not normally found in appreciable numbers in the antral mucosa.

\section{IMMUNOCYTOCHEMICAL TECHNIQUES}

These techniques depend upon raising antibodies to a natural or synthetic polypeptide hormone and reacting the purified antibody with granules suspected of containing the hormone in a suitably preserved tissue section. The reaction can be visualised either by 'tagging' the antibody directly with a fluorochrome or with horseradish peroxidase and subsequent histochemical demonstration of the enzyme. Alternatively the antibody attached to the peptide may be shown by using a second labelled antibody directed against it, the so-called indirect sandwich type technique. There is no doubt that such techniques are the most specific and reliable available for polypeptide identification and have been responsible for virtually all the advances in our knowledge in the last decade (see Dawson, 1976; Pearse et al. 1977).

Nevertheless there are problems associated with their use which deserve mention.

\section{Raising the antibody}

This depends primarily on having a suitable synthetic or suitably purified natural antigen, and on reliable techniques for immunisation, purification, and standardisation of the antibody. These will not be discussed further here. A few reliable antibodies are available commercially but most have to be raised in individual laboratories where the necessary expertise exists. Since a number of different polypeptides have closely related antigenic structure, cross reaction can be a problem.

\section{Preserving the tissue antigen}

The maintenance of antigenicity in tissue sections depends on the preservation of determinant sites and peptide configuration. Many fixatives, notably aldehydes, interfere with these determinant sites (Avrameas, 1973) and special bifunctional crosslinking substances, such as diethyl pyrocarbonate used as a vapour fixative on freeze dried tissue (Pearse et al., 1974), or p-benzoquinone in vapour or aqueous form (Pearse and Polak, 1975), may be required. The antigenicity of gastrin, pancreatic glucagon, and insulin is not affected by formaldehyde fixation or paraffin embedding and, given the appropriate antisera, identification of these hormones on ordinary tissue sections is within the compass of any competent histopathologist.

\section{Choice of technique}

Whether a fluorescent or an immunoperoxidase technique is selected, indirect (two or three stage) techniques are, in my view, generally preferable. Most antisera to gastrointestinal hormones are raised in rabbits, and good commercial goat or sheep anti-rabbit sera already tagged with fluorescein or peroxidase are available. On the whole, fluorescent techniques are easier to perform; they have the disadvantages of needing a fluorescence microscope, and the relevant fields must be photographed as the preparations are not reliably permanent. They do not allow ready visualisation of surrounding tissues unless phase contrast is used, so that orientation can be a problem. Peroxidase techniques are more complex and background staining and the presence of endogenous peroxidase can raise problems, but the preparation can be viewed under ordinary light, it is permanent, and surrounding structures can be visualised. On balance, I prefer them. Careful controls are essential.

\section{ULTRASTR UCT URAL TECHNIQUES}

Ultrastructural studies using controlled glutaraldehyde-osmium fixation and subsequent 'staining' show that secretory granules vary in size, shape, and electron density according to the substances they contain. It is probable that granule configuration is dependent on polypeptide rather than on amine content and that it reflects the nature, the chemical configuration, and the amount of stored material. It is possible to classify endocrine cells by measurement and description of their granules and the internationally accepted Wiesbaden classification is based on such observations (Solcia et al., 1973). It does not enable the contents of the granules to be identified, for which parallel topographical, immunocytochemical, and histochemical studies, assisted sometimes by radioimmunoassay of tissue extracts are required. There are a number of ways of achieving such correlation.

\section{Histochemical-ultrastructural correlation}

Within the human ileum the majority of endocrine cells are argentaffin, diazo positive, and show formaldehyde-induced fluorescence, confirming their 5HT content. A smaller number are argyrophil, but not argentaffin, and include cells with differing granular content. Ultrastructurally, the majority of ileal endocrine cells contain pleomorphic dense granules of variable shape, some of which are oval, some cigar shaped, and some angulated. Similar granules are found in proven 5HT secreting 'carcinoid' tumours but are rarely seen in those parts of the bowel in which argentaffin and diazo positive cells are infrequent. The relationship of the histochemical reaction to the granular appearance can therefore be inferred, but is in no sense proven. Indeed, the ultra- 
structural appearance is likely to be related to the presence of a polypeptide kinin rather than to the presence of 5HT.

\section{Histochemical-immunological correlation}

It is in some instances practicable first to identify the granule content of a particular cell using an immunofluorescent antibody technique and to photograph it. Fluorescence may then be quenched by immersion in formaldehyde, after which histochemical staining may be performed on the same section. The latter can then be correlated topographically with the immunofluorescent photographs. This has been done successfully for gastrin (Bussolati and Pearse, 1970) and other hormones.

Most combined techniques suffer from the disadvantage that, using ordinary serial sections of 5 to $6 \mu$ thickness, more than one technique cannot be applied to any one cell. This can be obviated in two different ways.

\section{(1) Semithin-thin section technique}

This ingenious technique, first perfected by Bussolati and Canese (1972) requires resin embedded tissue fixed in aldehyde alone, without osmium. A semithin $(1$ to $2 \mu$ ) section is cut first, followed by a number of ultrathin sections, followed by another semithin section for use as a control. Since the total thickness cut is only a fraction over $4 \mu$ the same cell can be included in all sections. An appropriate immunocytochemical technique is then applied to the first semithin section, while the ultrathin sections are used for studying the granules under the electron microscope. This allows a direct comparison between an immunocytochemical and an ultrastructural technique on the same cell. The antigen must not be denatured by the fixative or the embedding procedures, which limits the value of the technique.

This type of approach is capable of considerable expansion. The fixative can be varied to include substances such as carbodiimide, which preserves a wider range of antigens. Resin sections of $1 \mu$ thickness can be used for immunocytochemistry, allowing the investigator to include silver staining or other histochemical techniques at light and electron microscopical level among the investigations which can be made on a single cell (Polak et al., 1975).

\section{(2) Immunoelectron cytochemistry}

In this type of technique antibody is applied to a single ultrathin section. A peroxidase type technique is necessary to produce an electron dense reaction product and the antigen must not be denatured in preparation (Pearse et al., 1977). Further ultrathin sections embracing the same cell are then available for other studies.

\section{Conclusions}

The most reliable techniques for the identification of $\frac{\overline{0}}{\bar{m}}$ endocrine cells are immunocytochemical. The two principal factors which limit their use are the preservation of the antigenicity of polypeptides hormones and the raising and purifying of individua $\vec{\sigma}$ antibodies. Ultrastructural observation of granularsize, density, and shape are valuable, but essentially. need to be correlated with immunocytochemistry or radioimmunoassays of tissue extracts. Histochemica $\mathrm{P}$ techniques can be 'specific' for 5HT as being the only reactive biological amine identifiable in endo- 0 crine cell granules under normal circumstances, $\vec{\sim}$ but are of screening value only for polypeptideo hormones. The wholesale transfer of findings in normal granules to the identification of granules seen in endocrine cell tumours presents many problems outside the scope of this discussion.

\section{References}

Avrameas, S. (1973). Enzyme markers: their linkage witho proteins and use in immuno-histochemistry. In Fixation in Histochemistry, pp. 183-192, ed P. J⿳亠丷厂 Stoward. Chapman and Hall, London.

Barter, R., and Pearse, A. G. E. (1955). Mammalianฉ enterochromaffin cells as the source of serotonin $(5 \vec{F}$ hydroxytryptamine). Journal of Pathology and Bacterio $\frac{9}{3}$ $\log y, 69,25-31$.

Björklund, A., and Falck, B. (1968). An improvement of the histochemical fluorescence method for monoamines:Journal of Histochemistry and Cytochemistry, 16? 717-720.

Bussolati, G., and Canese, M. G. (1972). Electron microscopical identification of the immunofluorescents gastrin cells in the cat pyloric mucosa. Histochemie 29, 198-206.

Bussolati, G., and Pearse, A. G. E. (1970). Immuno음 fluorescent localization of the gastrin-secreting G cells in the pyloric antrum of the pig. Histochemie, 21, 1-4을.

Bussolati, G., Rost, F. W. D., and Pearse, A. G. E. (1969) Fluorescence metachromasia in polypeptide hormones producing cells of the APUD series, and its significances in relation to the structure of the precursor proteinN Histochemical Journal, 1, 517-530.

Clara, M. (1957). Uber die Morphologie und Histo chemie der basalgekörnten Zellen. Acta Neurovegetativd 16, 294-312.

Corrodi, H., and Jonsson, G. (1967). The formaldehyde F $^{+}$ fluorescence method for the histochemical demonstra-O tion of biogenic monoamines. A review on the metho dology. Journal of Histochemistry and Cytochemistry

15, 65-78.
Dawson, I. M. P. (1970). The endocrine cells of the gastro $\frac{\mathbb{Q}}{\sigma}$ intestinal tract. Histochemical Journal, 2, 527-549.

Dawson, I. M. P. (1976). The endocrine cells of the gastro? intestinal tract and the neoplasms which arise from them. Current Topics in Pathology, 63, 222-258. 
Ewen, S. W., and Rost, F. W. D. (1972). The histochemical demonstration of catecholamines and tryptamines by acid- and aldehyde-induced fluorescence: microspectrofluorimetric characterisation of the fluorophores in models. Histochemical Journal, 4, 59-69.

Grimelius, L. (1968). A silver nitrate stain for $\alpha 2$ cells in human pancreatic islets. Acta Societatis Medicorum Upsaliensis, 73, 243-294.

Hellerström, C., and Hellman, B. (1960). Some aspects of silver impregnation of the islets of Langerhans in the rat. Acta Endocrinologica, 35, 518-532.

Pearse, A. G. E. (1968). Common cytochemical and ultrastructural characteristics of cells producing polypeptide hormones (the APUD series) and their relevance to thyroid and ultimobranchial $C$ cells and calcitonin. Proceedings of the Royal Society B, 170, 71-80.

Pearse, A. G. E. (1969). The cytochemistry and ultrastructure of polypeptide hormone-producing cells of the APUD series and the embryologic, physiologic and pathologic implications of the concept. Journal of Histochemistry and Cytochemistry, 17, 303-313.

Pearse, A. G. E., and Polak, J. M. (1975). Bifunctional reagents as vapour- and liquid-phase fixatives for immunohistochemistry. Histochemical Journal, 7, 179-186.

Pearse, A. G. E., Polak, J. M., Adams, C., and Kendal, P. A. (1974). Diethylpyrocarbonate, a vapour-phase fixative for immunofluorescence studies on polypeptide hormones. Histochemical Journal, 6, 347-352.

Pearse, A. G. E., Polak, J. M., and Bloom, S. R. (1977). The newer gut hormones. Cellular sources, physiology, pathology and clinical aspects. Gastroenterology, 72, 746-761.

Polak, J. M., Pearse, A. G. E., and Heath, C. M. (1975). Complete identification of endocrine cells in the gastrointestinal tract using semithin-thin sections to identify motilin cells in human and animal intestine. Gut, 16, 225-229.

Sevier, A., and Munger, B. C. (1965). A silver method for paraffin sections of neural tissue. Journal of Neuropathology and Experimental Neurology, 24, 130-135.

Singh, I. (1964). A modification of the Masson-Hamperl method for staining of argentaffin cells. Anatomischer Anzeiger, 115, 81-82.

Solcia, E., Capella, C., and Vassallo, G. (1969). Leadhaematoxylin as a stain for endocrine cells: significance of staining and comparison with other selective methods. Histochemie, 20, 116-126.

Solcia, E., Pearse, A. G. E., Grube, D., Kobayashi, S., Bussolati, G., Creutzfeldt, W., and Gepts, W. (1973). Revised Wiesbaden classification of gut endocrine cells. Rendiconti di Gastro-enterologia, 5, 13-16.

Solcia, E., Vassallo, G., and Capella, C. (1968). Selective staining of endocrine cells by basic dyes after acid hydrolysis. Stain Technology, 43, 257-263. 